\title{
Investigate the Child's Scientific Activities on Practical Child's Activity Books for the Kindergarten's Children
}

\author{
Intisar Turki ALdarabah ${ }^{1}$ \& Reham Al-Mouhtadi ${ }^{1}$ \\ ${ }^{1}$ School of Education, Al-Hussein Bin Talal University, Ma'an, Jordan \\ Correspondence: Intisar Turki ALdarabah, School of Education, Al-Hussein Bin Talal University, P.O. Box (20), \\ Ma’an, Jordan. Tel: 962-798-108-464. E-mail: Entesusm@yahoo.com
}

Received: October 27, 2014 Accepted: December 2, 2014 Online Published: March 29, 2015

doi:10.5539/ies.v8n4p68

URL: http://dx.doi.org/10.5539/ies.v8n4p68

\begin{abstract}
This research aimed to investigate the extent to which the interactive international curriculum is included in the "Child's Scientific Activities" issued by the Ministry of Education in Jordan, for the kindergarten stage according to the global criterion (NRC). In order to answer the study questions, an instrument was developed to measure the extent of including the interactive international curriculum "The Child's Scientific Activities" for the Kindergartens' stage in the scientific concepts. The instrument consisted of scientific concepts that involved three basic aspects, the physics sciences aspects, Biological Sciences aspects and Earth and space aspects. The number of concepts was (20) scientific concepts. The instrument's validity was tested through introducing it to specialists' reviewers. Also the stability analysis was tested by re-analysis; the stage time span between the analyses was one month. The statistic data and frequencies were used to investigate the availability of the scientific concepts in the interactive international curriculum for the kindergarten stage, depending on the study instrument which was built for the study's purposes, and to investigate the suggested scientific concepts to be included in the curriculum. The study results showed a list of suggested scientific concepts to be included in the curriculum. Also, the results exhibited the availability of the scientific concepts in the curriculum (16) scientific concepts from (20) concepts, by (80\%) According to the results, the study recommended the kindergarten curriculum designers to include the suggested scientific concepts, and to be presented in a structural balance, and in depth to be appropriate to the developmental characteristics at the kindergarten stage.
\end{abstract}

Keywords: scientific concepts, global standards (NRC), kindergarten stage

\section{Introduction}

\subsection{Introduce the Problem}

The effective education investment should include educational plans from which emerge the curricula that satisfy the child's needs, to develop his capabilities, and to fulfill his desires. The interest should be greater in the materials that support the child's growth, develop his creative thinking, his ability to solve the problems, and to provide him with the new methods for dealing with the rapid scientific \& technological development (Young \& Diamond, 2012). There is the need to care about teaching the sciences generally, and the appropriate scientific concepts particularly (Wells, 1994, p. 84). The concepts help in orienting, predicting and planning for any activity, they allow the organization and connection between the groups of the things and events, also learning the appropriate scientific concepts helps the children in understanding and investigating many things that attract their attention to the environment, they increase their ability to use the information in problem solving situations (Vygotsky, 1987, pp. 99-101).

One of the most important benefits from learning the appropriate scientific concepts is the reduction of environment complexity, since they classify the existing things and positions, and considers means to know the things that exist in the environment; also they reduce the need for re-learning when encountering any new situation or position (Badawi \& Tawfeeq, 2009; Wenham, 1995; Berkenkotter, 1994).

Learning the scientific concepts has great importance and many benefits, since they help the students in increasing their understanding of the scientific materials and the nature of the science, because they are more stable, and less subject to change than the information based upon a set of limited facts and information (Beaty, 2006). The basic concepts link between the facts, and clarify the relations, they also allow the link between 
groups of things, events and phenomenon (Harlen, 2006). They facilitate the environment, to reduce its complexity and to facilitate the studying, because the basic concepts classify great numbers of things and events, and the environmental phenomenon, gathering them in groups or in categories (Young \& Diamond, 2012; Al-sror, et al., 2006). Studying the basic concepts increases the students' interest in the sciences subjects, motivates them to deeply study and specialize in them, also increases their usage of the difference science functions that represent in explanation, control, prediction, and help in planning the types of the scientific activity to discover and learn new things (Beaty, 2004).

In addition, studying the basic scientific concepts helps in understanding and explaining many things that attract the students attention to the environment, and increase their capabilities in using the information in developing the sense-motor perception, when the child organizes his different senses (Young \& Diamond, 2012), classifies them and adds to their forms: (Visual, acoustical, smelling and tasting), meanings that stem from the link of their meanings with the cognitive mental side (Beaty, 2003). The child's perception at the kindergarten stage is characterizes by his perception of the things, their forms and their spatial relation between, his perceptions about the colors, the relation with the forms, the different sizes and weights, then his perception of the time (ALdarabah, 2011).

To cultivate these benefits, many global institutions had been established with the interest in education for all the scholastic stages before the university education, such as the National Sciences Foundation (NSF), the American Association for the Advancement of Science (AAAS), and the National Science Teachers Association (NSTA), in order to achieve the objective which is to establish the cultured individual (American Association for the Advancement of Science (AAAS, 1993; Al-Shaeh \& Al-Oqaili, 2006). For this reason, these Associations had developed many of the teaching sciences projects, including the project that has been introduced by (AAAS) as a comprehensive initiative to improve the sciences education and learning (AAAS, 1993). This project has appeared in the year (1985), and called relative to the year in which (Hally Comet) will pass proximate to the earth (David, 2000; Martin et al., 2006). The project's organizers see that the child who inters the school in the year 1985 will witness all of the scientific and the technological changes through his life before the return of the (Hallu Comet) once again in the year (2061), (American Association for the Advancement of Science (AAAS, 1993), also the National Research Council (NRC) that pertains to the National Academy of Sciences has issued the National Science Education Standards (NSES).

These standards were derived from the (2061) project, where the (NRC) has coordinated the standards for sciences teaching from the kindergarten till the twelfth grade (Chen \& Siegler, 2001; Bakhtin, 1986). The standards were organized in the American Standards volume for the scientific education in seven chapters that included the principles upon which the standards were built, and their definitions (Gallas, 1995). In addition to standards for teaching sciences, professional growth for the sciences teachers, standards for content evaluation, standards for the scientific education and the scientific education system (NRC, 1996). Similarly, the educational system in Jordan has witnessed great changes in the educational plans (Haroon, 2005). The greater portion was for the early childhood stage, when the educational law Number (3) was issued in the year (1994) that has asserted the importance of the kindergarten stage, which is a formal un compulsory stage, kindergartens were established in many of the public schools, with the interest in the remote locations because of the absence of the private sector's contributions to them, to make the pre-school education available for all (Haroon, 2005).

Thanks to his Majesty King Abdullah the Second and Queen Rania Al-Abdullah,who pay great interest and care for childhood, the national strategy was prepared for the early childhood in the year (2000) by the guidelines from Queen Rania the needs and the specifications that distinguish the age groups in the stage were identified, this has led to the increase in the number of the kindergartens especially in the remote regions, the number till the year (2000) has reached (15) kindergartens in the remote region, this number has increased to (250) kindergartens in the year (2004), (The National Center for Information, 2004).

Also, the national strategy for the early childhood has accomplished the national strategy, and the release of the Interactive National Curriculum for the kindergartens that has been confirmed by the education council and identified its experimental application to the public kindergartens starting from the second scholastic term for the year (2003-2004), then later this curriculum was developed, its first edition was released in its new form in (2007), including the ( Practical Child's Activity) Book, and My Book: The activities in the Arabic language , and the activities in English language (Al-Saudi \& Al-Maneh, 2010). Because of the modernity of the kindergartens experiment in Jordan, and the endeavor for more development to keep pace with the distinguish global experiment in this regard, this study came to analyze the national interactive curriculum for the kindergartens, and to know the extent of their commitment to include the scientific and the healthy concepts that came in the national standards for the sciences education (NSES), and determining the fields that might need 
development or modification.

\subsection{Literature Review}

Senocak et al. (2013) had conducted a study about the scientific concepts and the scientific inquiry at the kindergarten stage, the study aimed at developing an instrument for measuring the extent to which the kindergarten's children comprehend the scientific concepts, and the scientific search processes specific to the pre-school stage in the Turkish curricula. The results showed that the Turkish curricula for the pre-school stage contain the scientific concepts and the search processes that should be available.

Haury (2000), study came to analyze the life sciences books to determine the extent of achieving their goals from teaching the sciences according to the National Standards in the United States, content analysis was used that focused on the harmony between the standards and the content of the Biology books that their numbers reached (10) books, also the teachers' guides, the analysis focused on the following fields (the cell's structure and functions, energy materials and the transformations and the molecular foundation for the heredity). The study results showed that these books ignored most of the important concepts, since they focused on the superficial information instead of on the important information, also the examples and the illustrations were presented to the students in an abstract way rather than in a sensory way, and the students had received very little help from the book when performed the scientific activities.

Wang (1998), study aimed at investigating both the extent and the way of including the science history in the physics books for the secondary stage, study results showed that the paragraphs that had addressed the science history were in agreement with the American standards, also most of the examples specific to science history were superficial and lacked the deep elaboration. Manal (2014) study, "Evaluating the scientific concepts of the kindergartens students, the second level (5-6)" has been applied to the second stage of kindergartens' children in the Egyptian public schools in the first scholastic term from the scholastic year 2013-2014. The researcher has used the applied national standards in the Hashemite Kingdom of Jordan and the applied standards in Saudi Arabia and the Syrian Arab Republic. The results showed that the curricula contain in the other Arab countries.

AL-darabah (2014) has conducted a study to evaluate the quality of the public kindergartens in Jordan. Study sample consisted of (250) public kindergartens in the Jordanian schools. The researcher has used (Harmz) instrument applied in America after making the needed modifications by presenting it to a committee of experts specialized in the kindergartens to be suitable to the Jordanian society. The results revealed that the scientific side in the public kindergartens did not went according to what the interactive national curricula contained of scientific activities focus on the scientific concepts mentioned in the curriculum.

Al-Malahmeh (2008) has concluded an evaluative study of the first grade basic stage's books (the first, second and third), to determine the extent of the scientific sequence mentioned in the Syrian curricula. The researcher has used the Syrian national standards specialized in the psychological sciences and experts in the children affairs. The results showed that the curricula were not in accordance with the Syrian standards. Since they contained (17) standards out of (21) standards, the study called for the revision of the curricula by the specialist in the ministry of education.

Isailan (2011) conducted a study to evaluate the developed curricula for the first preparatory grade in the light of the global quality standards in the kingdom of Saudi Arabia in Om Al-Qura in Saudi Arabia. Study sample consisted of all the preparatory stage's books. The results revealed that the books of this stage did not consider the global standards to include the scientific concepts in the curriculum, since the books had mentioned (15) scientific concepts versus the scientific standards that included (22) scientific concepts for this stage.

\subsection{Statement of the Problem}

Childhood stage is one of the most important stages that the human might passes through his life (Adas, 2005), and considers one of the fastest stages of the linguistic growth regarding the achievement, expression and understanding. Since the global standards represent a test through which it is possible to issue the judgments about the different studying courses, and the extent of their quality, they can be used as the base to depend on in building and developing the curricula (Mahmood, 2006), so this study has relied on the global standards as a test and a measure for the judgment on the extent of inclusion the scientific concepts in the Interactive National Curriculum for the kindergarten's children in Jordan. Based on the previously mentioned, and because the Interactive National Curriculum considers the basic pillar for the children education in Jordan, this study comes to analyze the Interactive National Curriculum in Jordan concerning the extent of inclusion the scientific and the hygienic concepts according to the global standards. Also, to pin point its strengths and weakness, determining the fields that might need development or modification, detecting the extent of inclusion the scientific and the 
hygienic concepts that are globally recommended, and introducing the needed recommendations according to the results of this study.

\subsection{Questions of the Study}

This study seeks to answer specific question: what is the degree of inclusion the scientific concepts in the Interactive National Curriculum for the kindergarten's children according to the global standards?

Objectives of the Study

This study aims to investigate the scientific concepts in the National Interactive Curriculum for the kindergarten's children in Jordan according to the global standards (NRC, 1996).

\subsection{Significance of the Study}

Significance of the study stems from its responses to the most important issues of the present era at the global and Arabic level, which is the interest in the scientific educational curriculum in one of the most important stage that human passes through, which is the early childhood (Kindergarten). At the global level, the global standards were issued for educating the sciences specific to the pre-school education were issued (NRC, 1996). Because of the importance of including these global standards, and to achieve their goals to find the scientific cultured individual, this study came to know the extent of inclusion the hygienic scientific concepts in the Interactive National Curriculum. The significance of this study focuses on the evaluation process of the Interactive National Curriculum of the kindergarten that performs in the light of the international standards for educating the scientific concepts, also the study will provide a list of scientific concepts for the pre-school education stage (Kindergarten Stage) according to the international standards, that will benefit the researchers in the field teaching the sciences at this stage.

\section{Method}

The descriptive analytical method was used because of its relevance to the purposes of this study, through following the content analysis methodology that considers one of the scientific research methods. This method analysis the curriculum content, monitoring the phenomenon's, frequency mean quantitatively in an organized scientific way, un-based on self-impressions or on random treatment (Mohammad \& Al-Atheem, 2012). The use of this methodology is beneficial in describing the degree of including the scientific concepts in the used Interactive National Curriculum in Jordan for the scholastic year (2013-2014), to determine the extent of its consistency with the international standards for teaching sciences for the kindergarten stage. The study instrument was built based on these International Standards to achieve the objectives of the study.

\subsection{Study Population and Sample}

Study population which is the study sample consisted of the Interactive National curriculum for the kindergartens in Jordan for the preliminary stage, for the first and second scholastic term for the scholastic year (2013-2014). The Interactive National Curriculum consisted of (7) educational units distributed to the two scholastic terms. The educational units that were taught in the first term were: I and my kindergarten, my family and my animals, while the units that were taught in the second term were: My nation, my plants, my water and my land. The beginning of each scholastic unit divided into six fields: The ethical, emotional, social, linguistic, physical, hygienic, mental, cognitive and aesthetic fields, illustrating the educational unit came mostly in the form of educational activities.

\subsection{The Study Instrument}

This study aimed to know the extent of including the scientific concepts in the Interactive National Curriculum for the kindergarten's children in Jordan according to the global standards. To achieve that, the global standards for the sciences education were reviewed, they included the educational content's standards in the National Science Education Standards (NSES) document that the National Research Center in the United States has published in the year (1996), they included the science education standards from the kindergarten stage to (K-12), and the standards issued by the National Association for the sciences teachers. After translating these global standards, and studying all of the mentioned scientific concepts, and comparing them, there appeared the presence of difference in some of the concepts from one stage to another, so the concepts that were irrelevant to the Jordanian environment were excluded. Some of the concepts were taken into account because they considered adaptive to the technological age, the rapid development and to openness. Also there was a consensus on them in most sciences teaching standards in the United States, after that reviewing the previous literatures and the theoretical literature related to them, then determining the initial form of the study instrument that consisted of the proposed scientific concepts to be included in the Interactive National Curriculum for the kindergartens' 
children according to the global standards, they included (9) basic concepts and (20) sub-concepts distributed to three basic fields:

\section{(1) Physics Sciences \\ (2) Life Sciences \\ (3) Earth Sciences and Space Sciences}

\subsection{Validity of the Study's Instrument}

The instrument has been introduced to a committee of arbitrators, it consisted of (10) teaching staff members in the specializations sciences teaching methods, measurement and evaluation specialization, kindergartens' children and early childhood. This was to confirm its validity regarding the extent of its relevance to the specifications of the age stage of the kindergartens' children (6 years old), and the extent of the phrases clarity, the precision of the linguistic wording, the relevance of the list to achieve the objectives of the study, which means its relevance to measure what it has intended to measure. After taking in to consideration the arbitrators opinions the instrument was modified in the light of these opinions and suggestions.

\subsection{Reliability of the Study's Instrument}

The instrument's stability was confirmed through the stability of the analysis process, by conducting the analysis process three times, the researcher has conducted the analysis twice in a one month time span, while the other analyst has conducted the third analysis (Holsti) equation was used to calculate the stability coefficient between the researcher and herself, as follow (Taima, 2004).

$$
R=\frac{(\mathrm{Ci}, \mathrm{C} 2)}{(\mathrm{C} 1+\mathrm{C} 2)}
$$

Where: R: the stability coefficient, $\mathrm{C}$ : the category, code, $\mathrm{C} 1, \mathrm{C} 2=$ The number of the categories that the researcher himself agrees upon in the two times analysis, $\mathrm{C} 1+\mathrm{C} 2=$ The sum of the categories number that were analyzed in the two times, stability coefficient value reached (96\%), which is a high and accepted value to adopt the study instrument. While the stability coefficient (the agreement) for each field of the instrument's field is illustrated in Table 1.

Table 1. The agreement percentage for the analysis between the researcher and herself about the scientific concepts

\begin{tabular}{lc}
\hline The General Fields & The Agreement Percentage \\
\hline Physical Sciences & $100 \%$ \\
Life Sciences & $97 \%$ \\
Earth and Space Sciences & $86 \%$ \\
\hline
\end{tabular}

Cooper's equation was used to calculate the percentage of the researcher's analysis agreement with the other analyst, which is as follow (Madi \& Othman, 1999).

$$
\text { Stability Coefficience }=\frac{\text { Number of the agreed upon concepts }}{\text { Number of the agreed upon concepts }+} \times 100 \%
$$

Stability coefficient percentage reached (89\%) which is high and accepted to adopt the study instrument. While the stability coefficient (The Agreement) for each field of the instrument fields is illustrated in Table 2. 
Table 2. Agreement percentage of the researcher's analysis with the other analyst on the scientific concepts

\begin{tabular}{lc}
\hline The General Fields & The Agreement Percentage \\
\hline The Physics Sciences & $92 \%$ \\
The Life Sciences & $85 \%$ \\
The Earth and Space Sciences & \\
\hline
\end{tabular}

\section{Results}

To answer this question, the content analysis process was performed for the Interactive National Curriculum for the kindergarten's children in Jordan in the scholastic year (2013-2014), through the use of part one of the study's instrument, which is the part specific to the scientific concepts developed through reviewing the global standards of the scientific concepts for the kindergartens' children stage. Table 3 illustrates the frequencies and the percentages of the physics sciences concepts in the Interactive National Curriculum for the kindergartens' children.

Table 3. Frequencies and percentage of the scientific concepts for the physics sciences field in the interactive national curriculum for the kindergartens' children

\begin{tabular}{lllcc}
\hline $\mathrm{N}$ & The basic concepts & The sub-concepts & Frequencies & Percentages $\%$ \\
\hline 1 & Force and motion & The location & 3 & $3.1 \%$ \\
\hline \multirow{3}{*}{2} & \multirow{2}{*}{ Energy } & Light & 2 & $2.1 \%$ \\
& & sound & 4 & $4.1 \%$ \\
& heat & 1 & $1.0 \%$ \\
\hline \multirow{3}{*}{3} & \multirow{2}{*}{ The material characteristics } & The physics characteristics & 18 & $18.6 \%$ \\
\cline { 2 - 5 } & & States of the material & 4 & $4.1 \%$ \\
\cline { 2 - 5 } & & The magnetic & 1 & $1.0 \%$ \\
\hline \multirow{2}{*}{ Total } & & 38 & $39.2 \%$ \\
\hline
\end{tabular}

We notice from Table 3 that the total percentage of inclusion the physics concepts in the curriculum reached $(39.2 \%)$ relative to the sum of the scientific concepts, Also, it is clear from the table that the most frequent physics concepts in the curriculum were the physics specifications, their frequency percentage reached (18.6\%), followed by the magnetic and the states, their frequency percentage reached $(4.1 \%)$, also it was found that the heat and the magnetic concepts were less frequent concepts, the percentage of their frequency reached (1\%), while the curriculum lacked the presence of the gravity concept. To complete answering the study's question, the frequencies and the percentages of the scientific concepts within the life sciences field mentioned in the Interactive National Curriculum for the kindergarten's children were illustrated in Table 4.

Table 4. The frequencies and the percentage of the scientific concepts for the life sciences field in the interactive national curriculum for the kindergarten's children

\begin{tabular}{|c|c|c|c|c|}
\hline $\mathrm{N}$ & The basic concepts & The sub-concepts & Frequencies & Percentages $\%$ \\
\hline \multirow[t]{3}{*}{1} & Characteristics of the living beings & Classification composition & 20 & $20.6 \%$ \\
\hline & & The function & 4 & $4.1 \%$ \\
\hline & & & 4 & $4.1 \%$ \\
\hline 2 & $\begin{array}{l}\text { Living beings and their } \\
\text { environment }\end{array}$ & and the life & 8 & $8.3 \%$ \\
\hline
\end{tabular}




\begin{tabular}{|c|c|c|c|c|}
\hline \multirow[t]{3}{*}{3} & \multirow{3}{*}{$\begin{array}{l}\text { Living } \\
\text { Beings }\end{array}$} & \multirow[t]{2}{*}{ Life cycle, the heredity } & \multirow{3}{*}{$\begin{array}{l}6 \\
0\end{array}$} & \multirow{3}{*}{$\begin{array}{c}6.2 \% \\
0 \%\end{array}$} \\
\hline & & & & \\
\hline & & & & \\
\hline \multicolumn{3}{|c|}{ Total } & 42 & $43.3 \%$ \\
\hline
\end{tabular}

We notice from Table 4 that the total percentage of inclusion life sciences concepts in the curriculum reached (43.3\%). Also, it is clear from the table that the most frequent of life sciences concepts in the curriculum were the classification concepts, the percentage of their frequency reached $(20.6 \%)$, followed by the environment concepts and the life requirements, their frequency percentage reached (8.3\%). Also, found that the composition and the function concepts were less frequent life sciences concepts, their frequency percentage reached (4.1\%), and the curriculum has lacked the heredity concept. To complete answering the question, the percentages and the frequencies for the third domain of the scientific concepts which is the earth and the space sciences domain were calculated, as illustrated in Table 5.

Table 5. Frequencies and percentage of the scientific concepts for earth and space sciences in the interactive national curriculum for the kindergarten's children

\begin{tabular}{lllll}
\hline $\mathrm{N}$ & The basic concepts & The sub-concepts & Frequencies & Percentages \% \\
\hline 1 & Space sciences & The space & 0 & $0 \%$ \\
2 & Change in the earth and the weather & The weather & 11 & $11.3 \%$ \\
3 & Elements of the earth planet & Land's material and components & 6 & $6.2 \%$ \\
\hline
\end{tabular}

We notice from Table 5 that the total percentage of inclusion earth and space sciences' concepts in the curriculum reached (17.5\%), also it is clear from table that the most frequent earth and space sciences' concepts in the curriculum were the weather concepts, their frequency percentage reached $(11.3 \%)$, followed by earth materials and components, their frequency percentage reached (6.2\%), while the curriculum has lacked the space concept and the earth surface changes concept. While the basic fields percentages for scientific concepts in the Interactive National Curriculum were illustrated in Table 6.

Table 6. Frequencies and the percentage of the scientific concepts for the basic field in the curriculum

\begin{tabular}{llcc}
\hline $\mathrm{N}$ & The fields & Frequencies & Percentages \% \\
\hline 1 & Physics sciences & 38 & $39.2 \%$ \\
2 & Life sciences & 42 & $43.3 \%$ \\
3 & Earth and space sciences & 17 & $17.5 \%$ \\
\hline Total & 97 & $100 \%$ \\
\hline
\end{tabular}

It is clear from Table 6 that the most available scientific concepts in the curriculum were life sciences concepts, since their frequency percentage reached (43.3\%) and the less frequent concepts were earth and space concepts, their percentage reached (17.5\%). Regarding the scientific concepts that included in the curriculum relative to the global standards is illustrated in Table 7.

Table 7. The scientific concepts mentioned in the global standards instrument and included in the interactive national curriculum

\begin{tabular}{llll}
\hline $\mathrm{N}$ & The fields & The basic concepts & The sub-concept \\
\hline 1 & Physics sciences & Force and motion & Location force speed \\
\hline
\end{tabular}




\begin{tabular}{|c|c|c|c|}
\hline & Energy & The light & \\
\hline & & The sound & \\
\hline & & The heat & \\
\hline & Material's Characteristics & The physics characteristics & \\
\hline & & States of the material & \\
\hline & & The magnetic & \\
\hline 2 & Life sciences & Living beings & Classification \\
\hline & & Characteristics & Compensation \\
\hline & & Living beings and their environments & function \\
\hline & & Life cycle of the living beings & The environment \\
\hline & & & and the life requirements life cycle \\
\hline 3 & Earth and space sciences & Changes in the earth and the weather & The weather \\
\hline & & & The earth's materials and components \\
\hline & & 16 concepts $=80 \%$ & \\
\hline
\end{tabular}

We notice from Table 7 the illustration of the scientific concepts that were included in the curriculum that reached (16) concept out of (20) concepts in the global standards instrument for the scientific concept with a percentage that reached $(80 \%)$, when excluding from this percentage of the concepts that had been repeated in the curriculum. Table 8 shows the scientific concepts percentages that were included in both the global standards and the curriculum.

Table 8 . The inclusion of the scientific concepts in the interactive national curriculum relative to the global standards

\begin{tabular}{llll}
\hline The field & $\begin{array}{l}\text { Number of the scientific concepts } \\
\text { in the global standards' list }\end{array}$ & $\begin{array}{l}\text { Number of the scientific concepts } \\
\text { that were included in the curriculum }\end{array}$ & Percentage \\
\hline Physics sciences & 10 & 9 & $90 \%$ \\
Life sciences & 6 & 5 & $83 \%$ \\
$\begin{array}{l}\text { Earth and space } \\
\text { sciences }\end{array}$ & 4 & 2 & $50 \%$ \\
\hline
\end{tabular}

We notice from Table 8 the percentages of the scientific concepts for each field of the fields relative to the percentage that it is supposed to be available according to the global standards. The percentage of the availability of physics sciences concepts reached $(90 \%)$, and life sciences $(83 \%)$, while the percentage of the availability of earth and space sciences concepts reached $(50 \%)$.

\section{Conclusion}

The study has reached the preparation of a list of proposal scientific concepts to be included in the Interactive National Curriculum for the kindergartens' children stage, the number of the scientific concepts is (20) concepts distributed within three basic fields (physical sciences, life sciences and earth and space sciences). This proposed list has been built in the light of the global standards for teaching sciences, in response to the reforms movements of the scientific curriculum to follow the scientific and the technological development. A team consisted of (22) specialized experts in sciences education, and with the participation of (18) thousands individuals from different American states and many other countries to develop and improve their teaching and learning process. They had introduced these standards to guarantee the quality of the educational process in its all inputs and outputs. Regarding the knowledge that the learner acquires and to be able to perform it, and the educational content, the educational programs teachers support. So they form guidelines to set the scientific content that will be introduced to the learner, and also to receive high quality expectations for the educational process output, through that content. The guidelines confirm the necessity for all the learners to acquire the information and the skills included in these standards regardless of the differences between those learners (NRC, 1996). 
In order to follow the global movement for the curricula development, and to comprehend the tremendous amount of knowledge and the technological development, this study came with the interest in these issues. Its instrument has been built that considers containing most of the scientific concepts according to the global standards for teaching sciences and health that should be included for the kindergartens' children's. If the focus places on them when planning and building the Interactive National Curriculum for them, the objective from teaching them will be achieved globally, which is finding the scientific cultured individual. This result agrees somehow with the results from some other studies, such as Al-Twaisi and Al-Shaweesh (2013), Al-bashayreh et al. (2007), Talafha and Abuhassan (2007), and Abu hola and Al-balawi (2006).

It was found from analyzing the content of the Interactive National Curriculum for the kindergartens' children that the scientific content included (16) scientific concepts out of (20) concepts from the concepts included in the proposed list (study instrument) by (80\%), this means that the curriculum contains a high percentage of the scientific concepts, this percentage attributes to the development of the Interactive National Curriculum by a specialized national team in the early childhood, and under the supervision of the National Committee for pre-school education development that correspond with the developmental specification of this important age group. The interest in developing the pre-school education came as one of the components of the project for education development project of the knowledge economy. The most important accomplishment of this project was the release of the Interactive National Curriculum that was appropriate to the child and his different growth stages (Barham, 2005). As part of the knowledge economy project for the pre-school education stage, came the interest in the scientific concepts that consider the basic pillars for the child to acquire the information, training him to use the scientific thinking method, and training him to observe (Bdair, 1995), and providing him with the scientific attitudes, skills and trends. Also, making him familiar with self-dependency, satisfying the child's need for the scientific knowledge, feeling of his importance as a human who has a positive role in the life, training him to search, explore and inquiry love (Badawi \& Tawfiq, 2009), helping him in understanding the world around him, and the direct contact with the nature that surrounds him (Botros, 2014). This result regarding achieving the sciences education's goals at the global level agrees with studies like Isailan (2011), Al-Mahrooki (2009), Khataiba and Shaili (2007), and A-Loolo (2007). Regarding the importance of teaching the scientific concepts for the kindergarten children's stage, this study agrees with studies such as, Senocak et al. (2013), Al-bashayreh et al. (2007).

Concerning the degree of the scientific concepts availability according to each field of the three fields, it has been found that (9) concepts out of (10) concepts within the first fields (physics sciences), by (90\%), this is a high percentage, while addressing the location concept (above, below, right, left, in front \& behind), the concept did not address the movement's direction (approaching or moving away). Regarding the force concept, the curriculum did not clarify that the pulling and pushing change the speed and the direction of the moving things, and did not describe the objects' movement (fast, slow \& fixed). The same thing for the magnet concepts, they did not show the important applications, about for the light's concept, the child was not introduced to the definitions of the natural and artificial light sources' concept. The content has lacked the gravity concepts that are difficult to teach at this stage, also the difficulty in explaining the phenomenon upon which the concept has been built, (Al-sherbeeni \& Sadeq, 2005). This considers a shortage in the Interactive National Curriculum for the kindergartens' children, because of the importance of the gravity concept for this stage, since it develops the child's observation, teaches him the prediction methods, this has received the consensus by the global standards for learning the sciences at this stage (NRC, 1996).

According to the second field, (life sciences) that included (6) concepts, five concepts out of the six concepts were available in the Interactive National Curriculum for the kindergartens' children, with the percentage (83.3\%), which is a high percentage, since mentioned in the curriculum two units, one about the plants (my plants), and the other about the animals (my animals). Regarding the living beings specifications' concepts, the plants and the animals, the curriculum contained many of the examples about the living beings in an attractive and smooth way, such as the environment, animals and birds their shape, nutrition, proliferation, living, and ways of taking care of them. Also, the curriculum has showed that the plants are not only for nutrition; rather they have many other benefits, such as using them in the timber industry and medicine.

In addition to the presence of kinds of plants that are not for eating. The curriculum focused on the importance for the child to know the plants' need for air, light and water for their growth, also has addressed the fifth senses concepts and their functions in an interesting educational method, also the living beings concepts and environments, have mentioned many of the examples, like the desert ship. Regarding the living beings life cycle's concepts, the curriculum has mentioned many examples about the life cycle's concepts, like the life cycle of the bean plant. The presence of two educational units about the animals and the plants in the kindergartens 
children's curriculum attributes to the importance of acquiring the child with the direct sensory experience about the scientific concepts, such as how the animals adapt to the environment, also they strengthen their observation power and satisfy their motive for investigation, since they consider one of the issues that form the source of pleasure and fondness for the kindergarten's child (Al-Sherbeeni \& Sadeq, 2005).

But the curriculum has lacked the heredity concepts, such as the acquired and the inherited characteristics, and the heredity characteristics that transfer from the fathers to the suns. It is necessary that the curriculum should include these concepts, because of their importance in providing the child with the integrated experience about the scientific concepts. Learning these concepts enriches the child's experience about what is going around him, and satisfies his love for investigation and knowledge. The reason behind the absence of the heredity concepts from the kindergartens children's curriculum might be that the curriculum planners believe that it is early to include these concepts in the curriculum, and they will be learnt in the following period of the child's age.

In the third field (earth and space sciences), the curriculum has included two concepts out of four concepts, by $(50 \%)$, which is a low percentage, since mentioned in the curriculum, the weather and its changes concept, the focus was on the child's knowledge about the specifications of the different seasons, and on the changes that take place in each season, to know the activities types that are appropriate for each season, and the relevant foods' types, the type of the cloths, and addressing the concept the Land's components and materials, but it lacked the space concept, which means monitoring the things in the sky, like the sun, the moon \& the stars, showing to the child their benefits and their most important specifications, he compares between them, also the absence of the earth's surface changes concepts, since the things at the earth's surface might witness the change over time. The change can be fast or slow, and these changes might be observable and measurable, while the absence of these concepts make the shortage in the experience introduced to the kindergarten's child, because till seven years old the child has the un-objectivity view about the universe. Regarding the objective or the phenomenon that the child observes at this stage, the child looks at the sun, moon, stars and others as living beings, they should be addressed to make the child aware of the scientific facts in this field according to his developmental characteristics, fostering his imagination and curiosity, answering his questions that enrich his experience and correct his knowledge, providing him with the scientific concepts that lead him to develop his logical and scientific thinking, strengthening his observation methods \& increasing his love to the sciences.

We notice from the previously mentioned how much of the experience the child will lose as the result of the absence of these concepts from the curriculum, there is the need for inclusion them to make the child possess the integrated experience in this field, the reason for the absence of these concepts from the kindergartens' children's curriculum might be the belief of the curriculum planners that these concepts are abstract and it is un preferable to learn them at this stage.

Also, we notice that the physics specifications' concepts, the living beings and the weather's specifications had gained the highest focus of the concepts in the curriculum, while the gravity, heredity, space, the earth surface changes concepts were absent from the curriculum. This might attribute to the absence of the fixed and planned strategy by the planners of the Interactive National Curriculum, also because of the lack of the participation by the specialists in the global standards to teach the sciences specific to this stage during the design of the curriculum. The highest focus was on, "I and my kindergarten", my plants", my animals and my land", while did not appear any concept in "my nation unit", and "my family unit" contained a small number of concepts. This shows the lack of balance in distributing the scientific concepts to the educational units, there is the necessity to care about addressing the scientific concepts in all of the educational units in equilibrium according to the concept's importance and learning them, because the concepts are the base of the cognitive structure, grow and develop by the increase of the child's experience with the mental growth (Badawi, 2003).

\section{References}

Abd al-Hakeem, I. L. (2014). Effect of a proposed programmed based on the active learning on developing some of the scientific concepts and some of the kindergarten children's mental skills (Unpublished doctorate desecration). Al-Menya University, Egypt.

Adas, M. (2005). An approach to kindergartens' children. Dar Al-Fikr, Amman, Jordan.

Al-bashayreh, Z. et al. (2007). The included scientific concepts in our Arabic Language book for the first three grades of the basic stage in Jordan. Ain Shams University, Journal of Education Faculty, 31(1).

Aldaraba'h, I. T. (2011). The quality of learning environment in government preschool in Jordan (Unpublished doctoral thesis). University of Since Malaysia.

Al-Lool, F. (2007). Level of physics topics' quality in the scientific books of the lower basic stage in the light of 
the global standards, work paper introduced to the Third Educational Conference. "Quality in the Palestinian Education": "Differentiation Approach" The Islamic University, Gaza (30-31 October).

Al-Saudi, F., \& Al-Maneh, A. (2010). Arabic language curricula in the pre-school stage. Journal of Education Faculty, 22(3). Alexandria University.

Al-Shaeh, F., \& Al-Oqaili, M. (2006). The extent of achieving the content's standards from the Kindergarten to (K-4) in the National Standards projects for the American Scientific Education (NSFS) in the sciences Books content in The Kingdom of Saudi Arabia. Work paper presented to the Tenth scientific conference "The present challenges and the Future Vision", The Egyptian Association for the Scientific Education, Ain Shams University (pp. 321-345).

Al-Sherbeeni, Z., \& Sadeq, Y. (2005). Children's scientific cognitive Growth. Cairo: Dar Al-Fikr Al-Arabi. Jordan.

Al-sror, N., Al-nablse, S., \& Abu-Taleb, T. (2006). Evaluate the performance of kindergarten children. Journal of Studies, 23(2), 332-356.

American Association for the Advancement of Science (AAAS). (1993). Benchmarks for science Literacy. New York: Oxford University Press.

Badawi, A., \& Tawfeeq, A. (2009). Scientific activities concepts for the Pre-school Child. Dar Al-Kotob, Cairo.

Badawi, R. (2003). Developing the sport concept and skills of the pre-school children. Dar Alfikr, Amman.

Bakhtin, M. (1986). Speech genres and other late essays. Austen, TX: University of Texas Press.

Bdair, K. (1995). The scientific concepts of the pre-kindergarten child. Alam Al-Kotop, Cairo.

Beaty, J. J. (2004). Skills for preschool teachers (7th ed.). New Jersey: Merrill Prentice Hall.

Beaty, J. J. (2006). Observing development of the young child (6th ed.). New Jersey, Merrill Prentice Hall.

Beaty, J. J., \& Pratta, L. (2003). Early literacy in preschool and kindergarten. New Jersey: Merrill Prentice Hall.

Berkenkotter, C. (1994). Scientific writing and scientific thinking: Writing the scientific habit of mind. Paper presented at the 'Lev Vygotsky and the Human Sciences' Conference, Moscow, September 1994.

Chen, Z., \& Siegler, R. (2001). Scientific concepts: Development in Children International (pp. 13714-13719).

David, H. (2000). High school biology textbooks Do Not Meet National Standards. ERTC Digest (ED46394).

Harlen, W. (2006). The Development of scientific concepts in young children. Educational Research, 11(1).

Haroon, R. (2005). Analytical study. "The integrative National Curriculum: The modern principles for the Kindergarten Children's Education and Bringing Up”. Work paper introduced to the First conference for childhood and the family. Al-hashemiya University.

Isailan, B. (2011). Evaluating the developed sciences book for the first intermediate grade in the light of the total quality standards (Unpublished master thesis). University of Om-Alqura.

Khatybeh, A., \& Al-Shili, A. (2007). Concerns of sciences textbooks' content for the fifth basic Grade in Jordan about The American National Standards. Journal of Al-Shariqa University for the Lawfulness and Humanitarian Sciences, 4(1), 163-179.

Mahmood, S. A. (2006). The concepts of the academic curriculum and the integrated development in the knowledge society: Educational visions for developing the Arab Human's Merits and His Development in a changing Environment. Alam Al-Kitab, Cairo.

Mohammad, W., \& Al-Atheem, R. (2012). Analyzing the curriculum's content in the humanitarian sciences. Dar Al-Maseera for publication. Amman.

National Research Council (NRC). (1996). Science-study and teaching-standards-United States. Washington, DC: National Academy Press.

Senocak, E. (2013). A study on development of an instrument to determine Turkish kindergartens students' understanding of scientific concepts and scientific inquiry processes. Educational Consultancy and Research Center.

The National Center for Information. (2004). Queen Rania Launch's the kindergarten children's curriculum in the Ministry of Education at the Beginning of the scholastic year 2004. Referred to the site date 18/9/2013.

Vygotsky, L. S. (1987). Thinking and speech. In R. W. Rieber, \& A. S. Carton (Eds.), The collected works of L.S. 
Vygotsky (Vol. 1: Problems of general psychology, Trans. N. Minick). New York: Plenum.

Wells, G. (1994). Learning and teaching "Scientific Concepts": Vygotsky's Ideas Revisited. Paper was presented at the Conference," Vygotsky and the Human Sciences," Moscow, Sept. 1994. University of Toronto.

Wenham, N. (1995). Understanding primary science. London, UK: Paul Chapman.

Young, H. S., \& Diamond, K. E. (2012). Two approaches to teaching young children science concepts, Vocabulary, and Scientific Problem-solving Skills. Early Childhood Research Quarterly, 27(2), 295-305. http://dx.doi.org/10.1016/j.ecresq.2011.09.006

\section{Copyrights}

Copyright for this article is retained by the author(s), with first publication rights granted to the journal.

This is an open-access article distributed under the terms and conditions of the Creative Commons Attribution license (http://creativecommons.org/licenses/by/3.0/). 